\title{
Water MobiLity AND Mold SusceptibiLity of ENGineERed Wood Products
}

\author{
X. Ye, S. Wang, R. Ruan, J. Qi, A. R. Womac, C. J. Doona
}

\begin{abstract}
There are significant environmental benefits of understanding the water characteristics in engineered wood products related to their fungi/mold susceptibility. The primary goal of this investigation was to gain a fundamental understanding of the water characteristics in oriented strandboard (OSB) using nuclear magnetic resonance (NMR) approaches. Isotherm sorption tests were conducted on commercial OSB specimens made from different wood species and adhesive combinations. Moisture content $(M C)$ determination, water activity $\left(a_{w}\right)$ measurement, and magnetic resonance relaxometry plus chemometrics analysis were performed on the OSB specimens during isotherm sorption tests. The results showed that neither MC nor $a_{w}$ is a reliable indicator of mold susceptibility of OSB. NMR relaxometry together with distributed exponential analysis detected that the state of water with the longest spin-spin relaxation time is responsible for the mold susceptibility of OSB. OSB made from southern pine had higher mold susceptibility than that made from aspen because the pine OSB had a third water component with very long spin-spin relaxation time (6035-7346 $\mu \mathrm{s})$. The results suggest that a new protocol for quality control based on NMR relaxometry could be put in place in OSB production.
\end{abstract}

Keywords. Distributed exponential analysis, Magnetic resonance, Oriented strandboard, Relaxometry, Water activity.

I ndoor mold growth is a suspected major health hazard, giving rise to allergic reactions, asthma attacks, and even toxic syndromes (Ross, 2004), and has been named in high-profile lawsuits. Over the past five years, mold growth has reigned as a top issue of the U.S. Environmental Protection Agency (EPA) indoor air quality program. Oriented strandboard (OSB), as a relatively new but very common component of houses, has become a focus of particular concern because it wets easily and has little resistance to fungal attack. The ability of microorganisms to grow in wood products is determined by the environment within the wood products themselves as well as by the environment surrounding them, designated respectively the intrinsic and extrinsic environments of a wood product. The intrinsic factors include nutrients, water characteristics, $\mathrm{pH}$, antimicrobial constituents, and biological structures. Research on mold and related moisture issues in wood-based products has long focused on the extrinsic factors through the control of heating, ventilation, and air conditioning (HVAC) systems.

Submitted for review in December 2005 as manuscript number SE 6239; approved for publication by the Structures \& Environment Division of ASABE in June 2006. Presented at the 2005 ASABE Annual Meeting as Paper No. 056129.

The authors are Xiaofei P. Ye, ASABE Member Engineer, Assistant Professor, Department of Biosystems Engineering and Soil Science, The University of Tennessee, Knoxville, Tennessee; Siqun Wang, Assistant Professor, Tennessee Forest Products Center, Knoxville, Tennessee; Roger Ruan, ASABE Member Engineer, Professor, and Jingning Qi, Research Associate, Department of Biosystems and Agricultural Engineering, University of Minnesota, St. Paul, Minnesota; Alvin R. Womac, ASABE Member Engineer, Professor, Department of Biosystems Engineering and Soil Science, The University of Tennessee, Knoxville, Tennessee; and Christopher J. Doona, Team Leader, Research Chemist, U.S. Army Natick Soldier Center, Natick, Massachusetts. Corresponding author: Xiaofei P. Ye, 2506 E. J. Chapman Dr., Knoxville, TN 37996; phone: 865-974-7266; fax: 865-974-4514; e-mail: xye2@utk.edu.
However, to the best of our knowledge, no systematic research has been done on the intrinsic factors that affect mold growth on wood products.

There is little information available on the dynamics of mold growth on oriented strandboard (OSB) or other building products. Morris et al. (2003) observed that OSB and other building materials did not support mold growth if the relative humidity $(\mathrm{RH})$ was below $85 \%$. Above that level, however, OSB and many other tested materials were susceptible to mold attack. The USDA Forest Products Lab Advanced Housing Research Center (2003) suggests that RH of $80 \%$ for one month is required to initiate mold growth, but this is only a general guideline and does not take into account variations in the characteristics of the OSB. Correcting the extrinsic moisture problem remains crucial to preventing growth of molds and other fungi over the longer term. Unfortunately, there is little available information relating time, moisture conditions, OSB properties, and mold growth, making it difficult to determine if a long-term moisture problem exists by observing the presence or absence of mold within the structure. An understanding of the dynamics of moisture infiltration into OSB exposed to high humidity and its relationship to mold initiation would greatly assist efforts to increase the resistance of OSB to mold through process and raw material manipulation. Such data could also be used to better predict the implications of specific construction practices that lead to moisture intrusion as well as ancillary research on building sealants and other water-excluding technologies.

A number of researchers have investigated the sorption isotherms of wood and wood-based products (Halligan and Schniewind, 1972; Hartley and Schneider, 1993; Niemz and Poblete, 1995; Sekino et al., 1999; Siau 1995; Simpson, 1973). Most of the research has been to characterize the sigmoid shape of wood-water vapor interactions and to provide partial insights into these interactions. None of the 
research approached the sorption issue from the aspect of mold growth. Moisture can exist in wood as water or water vapor in cell lumens (cavities) and as water "bound" chemically within cell walls. The moisture content at which cell walls are completely saturated (all "bound" water) but no "free" water exists in cell cavities is called the fiber saturation point (FSP). The FSP of wood averages about $30 \%$ moisture content (dry basis), but individual species and individual pieces of wood may vary by several percentage points from that value (Forest Products Laboratory, 1989). FSP is often considered as the moisture content below which the physical and mechanical properties of wood begin to change as a function of moisture content (Forest Products Laboratory, 1989). However, at non-equilibrium conditions, the bulk moisture content of the wood may not accurately reflect variations in water distribution throughout the piece. Thus, there is a need to develop a better and more precise measure of the "availability" of water for microbial growth.

Food microbiologists turned to water activity $\left(a_{w}\right)$ measurements upon discovering that microbial spoilage of foods occurred at widely varying water contents. Since moisture content alone was not a reliable indicator for microbial growth, Scott (1957) applied the water activity concept to describe the water available for microbial growth. Since then, extensive research has been conducted on the relationship between water activity and microbial growth in foods (Beuchat, 1981; Duckworth, 1981; Gervais et al., 1988; Labuza and Contreras-Medellin, 1981; Leistner and Rodel, 1976). The water activity concept has served microbiologists and food technologists for decades and is the most commonly used criterion in the control of food safety and quality. However, the water activity concept has not been introduced into the investigation of mold issues in wood-based products, which are also hygroscopic.

Although the water activity concept is now widespread, its universality has been questioned based on the results of several studies (Chinachoti and Schmidt, 1991; Labuza et al., 1972; Lang and Steinberg, 1981; Slade and Levine, 1991). It was pointed out (Ruan and Chen, 1998; Schmidt, 2004) that $a_{w}$ is a thermodynamic parameter that requires an equilibrium condition to be determined, but microbial growth is a dynamic process. Labuza et al. (1972) found that the $a_{w}$ needed to impede the growth of several microorganisms was lower if the food product was prepared by desorption rather than by adsorption. Lang and Steinberg (1981) reported that conidia germination of Aspergillus parasiticus was highly dependent on the nature of the substrate (e.g., starch versus sucrose) and less dependent on water activity. Thus, a more dependable, precise measure of the availability of water for microbial growth is greatly needed. Nuclear magnetic resonance (NMR) relaxometry enables the molecular mobility of water and food solids to be studied independently (Schmidt, 2004; Webb et al., 2001), providing a better understanding of the molecular mobility of water and solids in food systems (Ablett, 1992; Kalichevsky et al., 1994; Schmidt and Lai, 1991). Many studies have independently used water mobility (as monitored by NMR water relaxation times) as a measure of water availability (Ruan and Chen, 1998; Schmidt and Lai, 1991; Slade and Levine, 1991). However, little work has been reported on the relationship between water mobility and microbial attack in wood systems.
The objective of this investigation was to probe the relationship between fundamental water characteristics and mold growth in oriented strandboard (OSB) using nuclear magnetic resonance (NMR) approaches and compare the water characteristics measured by NMR with the moisture content (MC) and water activity $\left(a_{w}\right)$.

\section{Materials ANd Methods}

Samples of commercial OSB from six different mills were procured either directly from the mill or from the local market. Two thickness dimensions were obtained: 7/16 inch and 23/32 inch. Two resin types, phenol formaldehyde (PF) and polymeric diphenylmethane diisocyanate (MDI), and two wood species were chosen to represent the most common OSB products available in the U.S. and Canada (table 1). These commercial OSB products had no anti-mold treatment.

Three $28 \times 28 \times 6 \mathrm{~mm}$ blocks were cut from each OSB board as test specimens. The six faces of each specimen were carefully trimmed so that each was a newly exposed surface. The initial weight of each specimen was measured, and the water activity $\left(a_{w}\right)$ was determined at $25^{\circ} \mathrm{C} \pm 1.5^{\circ} \mathrm{C}$ using an Aqualab water activity meter (Decagon Devices, Inc., Pullman, Wash.). The Aqualab meter employs the chilled mirror method to determine the $a_{w}$ value in five minutes. In this time frame, only pseudo-equilibrium is reached. The $a_{w}$ value reflects water activity in the surface layer of the OSB specimen. Since mold growth on OSB is an aerobic surface phenomenon, the $a_{w}$ measured by the Aqualab meter showed the water activity environment in which mold grew. The usefulness of water activity measured under pseudo-equilibrium is discussed in detail by Schmidt (2004). The OSB specimens were then isothermally conditioned in the headspace of small desiccators containing water at $25^{\circ} \mathrm{C} \pm 1.5^{\circ} \mathrm{C}$ to provide relative humidity $(\mathrm{RH})$ conditions of $100 \%$ in the headspace. The specimens were weighed and measured for water activity at designated times and $25^{\circ} \mathrm{C} \pm 1.5^{\circ} \mathrm{C}$ during a month-long period of isotherm conditioning. At the end of the isotherm test, all specimens were oven-dried, following ASTM standard D4442-92, to back-calculate the moisture content (dry basis) of each specimen. Visual inspection of mold growth on the specimens was performed daily.

NMR relaxometry experimentation concurrent with the $a_{w}$ measurements was performed on a replicated set of OSB specimens exposed to $100 \% \mathrm{RH}$ at $25^{\circ} \mathrm{C} \pm 1.5^{\circ} \mathrm{C}$ to evaluate the change in relaxation times. All the NMR experiments were performed on a low-field benchtop NMR (MARAN DRX, Resonance Instruments, Ltd., Oxfordshire, U.K.) at $20 \mathrm{MHz}$. Two pulse sequences, namely, CPMG (named after

Table 1. Commercial OSB products used in the study.

\begin{tabular}{cccccc}
\hline \multirow{2}{*}{$\begin{array}{c}\text { Test } \\
\text { Board[a] }\end{array}$} & \multicolumn{2}{c}{ Resin Type } & & $\begin{array}{c}\text { Wood } \\
\text { Species }\end{array}$ & $\begin{array}{c}\text { Thickness } \\
\text { (inch) }\end{array}$ \\
\cline { 2 - 3 } 7 & Face & Core & & Aspen & $7 / 16$ \\
9 & PF & MDI & & Aspen & $7 / 16$ \\
10 & PF & PF & & Aspen & $7 / 16$ \\
14 & PF & PF & & Aspen & $23 / 32$ \\
15 & PF & MDI & & Southern pine & $23 / 32$ \\
16 & PF & PF & & Southern pine & $23 / 32$ \\
\hline
\end{tabular}

[a] Board numbers were assigned in consistency with previous research on comparative OSB properties (Gu et al., 2005; Wang et al. 2003). 


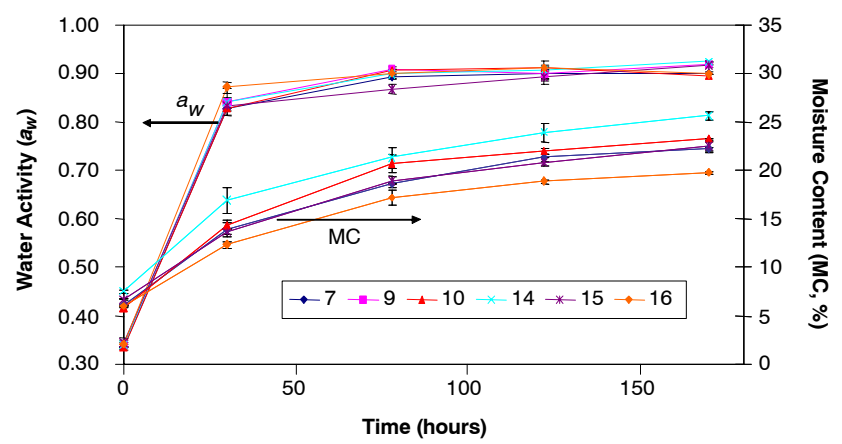

Figure 1. Water activity and moisture content changes of OSB specimens exposed to $100 \% \mathrm{RH}$ for up to $170 \mathrm{~h}$ at $25^{\circ} \mathrm{C} \pm 1.5^{\circ} \mathrm{C}$.

the four inventors: Carr, Purcell, Meiboom, and Gill) and inversion-recovery, were performed on each specimen in order to obtain the spin-spin relaxation time (T2) and spin-lattice relaxation time (T1), respectively. As suggested by Hills et al. (1989), the CPMG decay curve should be a summation of the continuous distribution of exponential decays that correspond to different states of water, and an infinite number of exponential components would be required to completely describe the relaxation behavior mathematically. Fortunately, developments in chemometrics enable the analysis of relaxation data assuming a continuous distribution of relaxation times (Butler et al., 1981; Remin et al., 1989). A computer program, WinDXP (Resonance Instruments, Ltd., Oxfordshire, U.K.), was used to conduct chemometrics analysis by fitting the continuous exponential distribution of $\mathrm{T} 2$.

\section{Results AND Discussion}

The isotherm experiment, using pure water instead of a saturated salt solution, simulated an accelerated process for mold growth. Colonized mold was first observed on the surface of all specimens from board 14 on the eighth day into the isotherm conditioning, followed by specimens from boards 15 and 16 on the next day. Boards 14, 15, and 16 were all made from southern pine. On the eleventh day into the isotherm conditioning, colonized mold appeared on specimens from board 10, followed by boards 9 and 7 on the twelfth day. Mold formation on aspen OSB obviously lagged behind that on pine OSB. The colonized mold attracted moisture, significantly increasing the moisture content in the

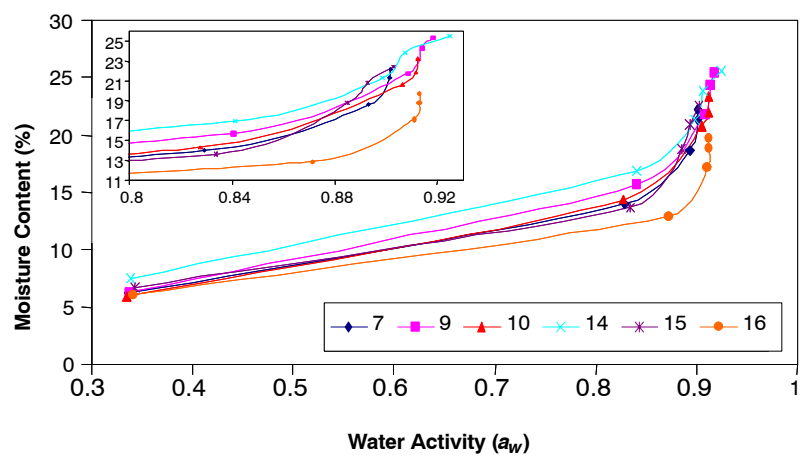

Figure 2. Isotherm plot of moisture content vs. water activity. Inset is a close-up of the high $a_{w}$ region. colony and on the neighboring OSB surface for continuous growth. This localized increase of MC interfered with the $a_{w}$ and NMR measurements, and those measurements made after visible colonization do not adequately reflect the mold susceptibility of the OSB specimens. Therefore, only data acquired in the first seven days are presented. The changes in moisture content and water activity during the seven-day period are presented in figure 1, together with the corresponding standard deviations.

After only $30 \mathrm{~h}$ of conditioning at $100 \% \mathrm{RH}$, the $a_{w}$ in the surface layer of the OSB specimens jumped from 0.33 to 0.83 and higher, which is generally high enough for spore germination (USDA Forest Products Lab Advanced Housing Research Center, 2003). However, the moisture content of the OSB specimens after $30 \mathrm{~h}$ treatment under $100 \% \mathrm{RH}$ was only between $12.3 \%$ and $16.9 \%$ because the samples had not reached equilibrium. Such MC levels are far below the fiber saturation point (about 30\% MC) and would be considered safe from attack by fungi. An isotherm plot of MC vs. $a_{w}$ reveals a sigmoid shape (fig. 2), which is consistent with the literature (Sekino et al., 1999; Siau, 1995; Simpson, 1973).

Specimens from board 16, which used only MDI adhesive, consistently showed lower moisture content than specimens from any other boards at the same time point. The isocyanate adhesive has been proven to react with the wood constituents to form cross-linkages that reduce the adsorptive nature of wood (Alexander et al., 2000). The moisture content of specimens from this board reached $19.7 \%$ at $170 \mathrm{~h}$, much lower than the $25.6 \%$ found for board 14 and the $22.5 \%$ for board 15 (fig. 1). The same trend was also observed in previous research, in which the water absorption after $96 \mathrm{~h}$ of water soaking was $84.9 \%, 64.4 \%$, and $35.2 \%$ for boards 14 , 15 , and 16, respectively (Gu et al., 2005). However, the $a_{w}$ of board 16 was 0.91 at the last time point, lower than the 0.925 of board 14, but higher than the 0.898 of board 15 . These results suggest that the adsorptive properties of an OSB specimen do not truly reflect the chemical potential for microbial growth as revealed by water activity.

According to the information provided by figures 1 and 2, it is difficult to tell which OSB specimen has higher mold susceptibility. Concurrent NMR experimentation provided richer and more detailed information than the $a_{w}$ and MC measurements. Figure 3 shows the changes of T1 and T2 during the isotherm sorption process.

NMR methods probe how water molecules interact with each other and with other wood constituents at the molecular level. "Availability" of water is a manifestation of how "freely" water molecules can participate in reactions or how easily water molecules diffuse to the reaction sites to participate in biochemical reactions. Many researchers have found that the mobility of water, as measured by NMR relaxometry, is related to the "availability" of water in complex systems (Hills et al., 1990; Kakalis et al., 1990; Lai and Schmidt, 1991, 1993; Schmidt and Lai, 1991). Very mobile water molecules take a long time to reach their equilibrium state, or relax very slowly; thus, they have long relaxation times. Spin-lattice relaxation time (T1) is the time constant characterizing the relaxation process whereby energy absorbed by the excited protons or spins is released back into the surrounding lattice, re-establishing thermal equilibrium. Therefore, $\mathrm{T} 1$ relaxation reflects the interaction between water molecules and other lattice molecules surrounding them. Spin-spin relaxation time (T2) is the time 

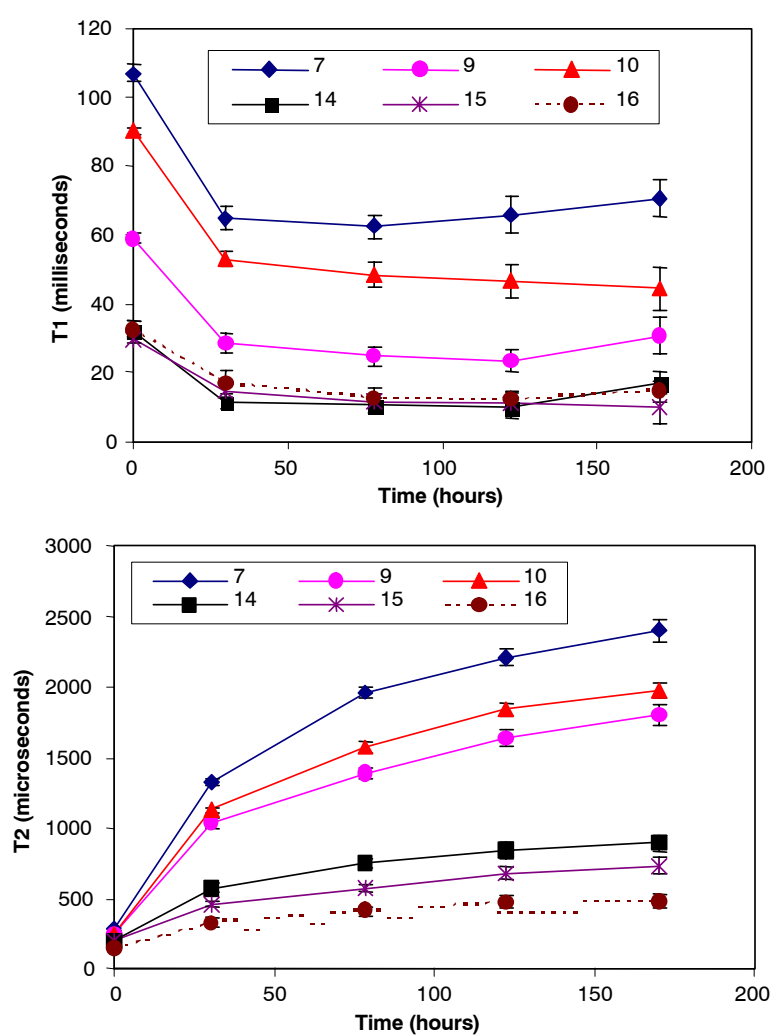

Figure 3. Change of relaxation times of OSB during isotherm sorption.

constant describing the exponential decay of the signal resulting from purely random spin-spin interactions in the transverse plane. The $\mathrm{T} 2$ relaxation reflects the interaction among water molecules. In biomedical magnetic resonance imaging (MRI), the values of T1 and T2 are unique for every kind of tissue, and this is what enables MRI to differentiate between different types of tissue.

As shown in the T1 plot of figure 3 , the water molecules needed some time to stabilize their interaction with and be bonded to the lattice molecules. On the other hand, the translational mobility (T2) of water increased as more moisture was absorbed. Importantly, the OSB specimens made from pine or aspen can be differentiated in the T1/T2 plots because the OSB made from aspen apparently had higher water mobility than the OSB made from pine. Nonetheless, visual inspection detected the earliest mold growth on the surface of specimens from board 14, which is made from pine. For better contrast, a picture taken at $\sim 700 \mathrm{~h}$ of conditioning shows that specimens made from pine had heavier mold covering their top surfaces (fig. 4). This observation is consistent with the findings of previous research (Laks et al., 2002) showing that aspen OSB was no more susceptible to mold than solid aspen and was in fact less susceptible than plywood made from pine.

Distributed exponential analysis of T2 using the WinDXP program (Resonance Instruments, Ltd., Oxfordshire, U.K.) revealed interesting information (fig. 5) that may explain the aforementioned contradiction between water mobility and mold growth observations. Figure 5 shows the T2 distributions for OSB test boards 10 and 14. Specimens from boards 7 and 9 showed a pattern similar to that of board 10, while specimens from boards 15 and 16 exhibited a pattern similar to that of board 14 .

For the OSB made from aspen (board 10), a bi-nodal shape of the $\mathrm{T} 2$ distribution characterizes the water mobility distribution (with the exception at time 0), indicating that there were two "states" of water. The distribution of the first state of water (the node with shorter T2 values) changed slightly, whereas the distribution of the second state of water shifted towards longer T2 values with time in the isotherm sorption process. These observations also hold true for the OSB made from pine (board 14). However, a third node appeared for the OSB made from pine at the last time point. This third state of water, with much longer $\mathrm{T} 2$ relaxation times, may explain the higher mold susceptibility of the OSB made from pine. It is suspected that this third node corresponds to the water component above the fiber satura-

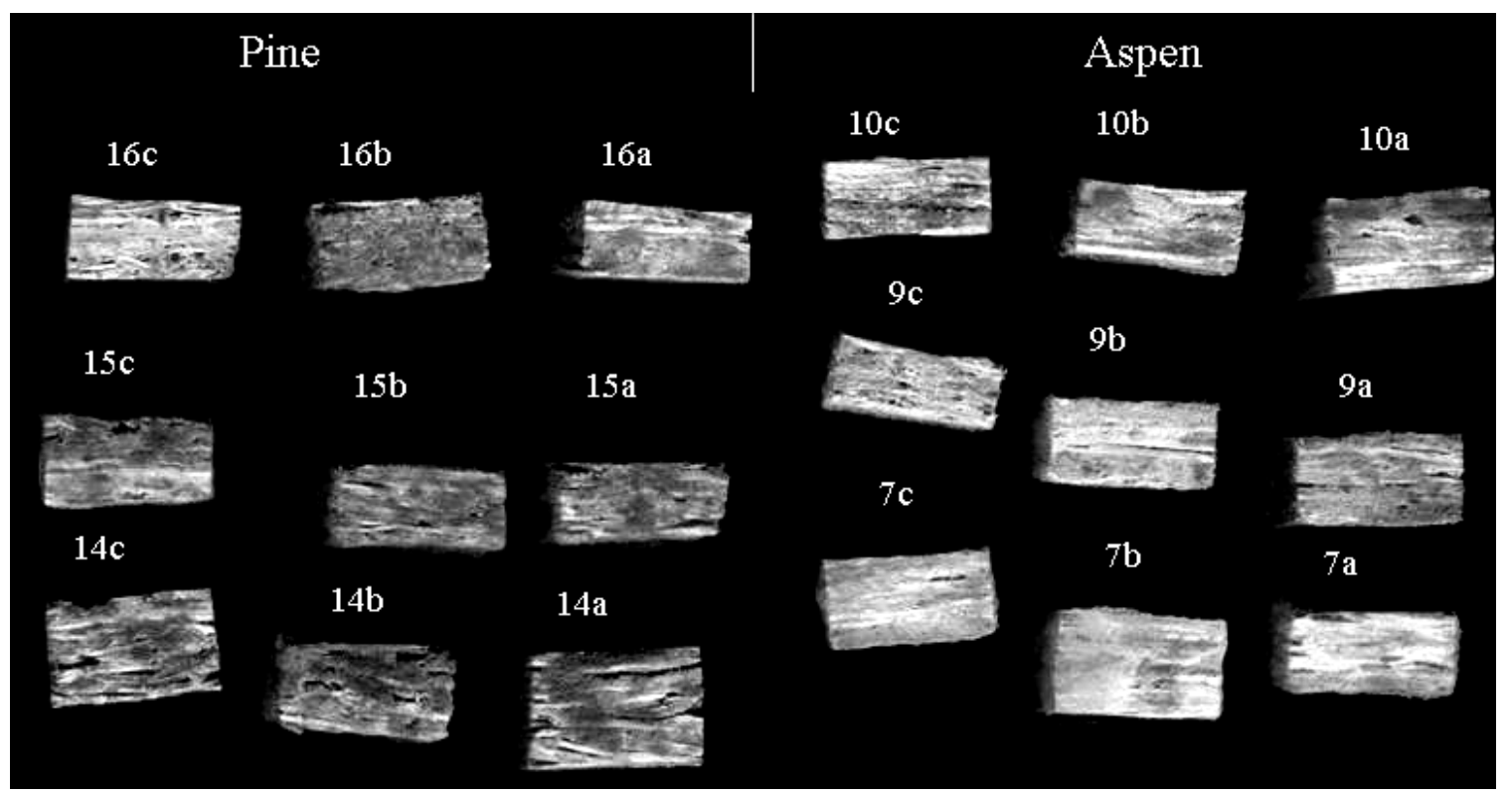

Figure 4. Gray-scale images showing mold growth on the top surfaces of tested OSB specimens $700 \mathrm{~h}$ into the isotherm sorption; darker spots contrasting with the lighter OSB background are mold. 

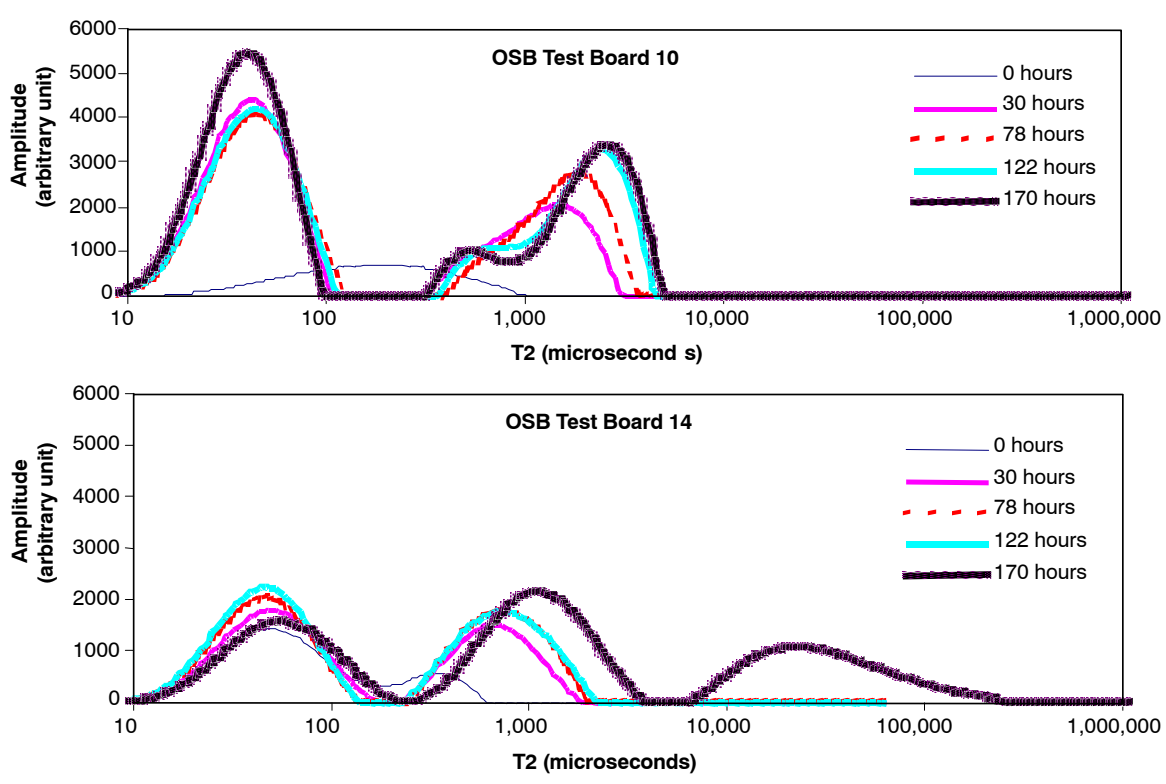

Figure 5. T2 distribution of OSB test boards 10 and 14 during isotherm sorption.

tion point (FSP), and the OSB made from pine has a lower FSP than that made from aspen, although further experiment is needed to confirm this. However, a literature search found that there is hardly any term in wood science that has been defined so many times as the term "fiber saturation point," and the discussion of how to define and how to measure this property is still going on (Babiak and Kudela, 1995).

Fitting to a bi-exponential distribution enables a closer look into the first two states of water mobility (fig. 6). Designating the short, medium, and long $\mathrm{T} 2$ components of water as T2S, T2M, and T2L, respectively, figure 6 shows the change of mobility of the first two states of water and the
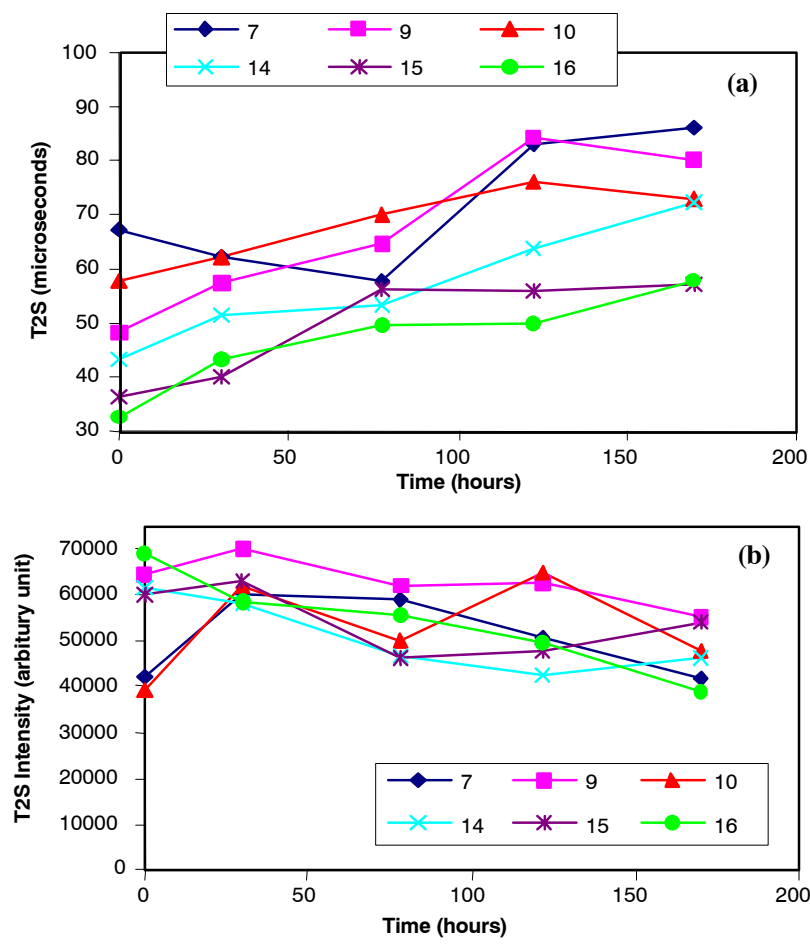

corresponding signal intensity (I), which is proportional to the proton density of the water components.

The short T2 (T2S) component had a small range, from 30 to $90 \mu \mathrm{s}$, and the medium T2 (T2M) component had values between 500 and $2600 \mu$ s. The long T2 (T2L) component reached to $7346 \mu \mathrm{s}, 6227 \mu \mathrm{s}$, and $6035 \mu$ s for boards 14, 15, and 16, respectively (not shown in the figure since these values only appeared for the OSB made from pine at the last time point). Board 14, with the heaviest mold covering, had the longest T2L. It is evident from figure 6 that both the relaxation time and the signal intensity of the medium component increased as more water was sorbed. Moreover,
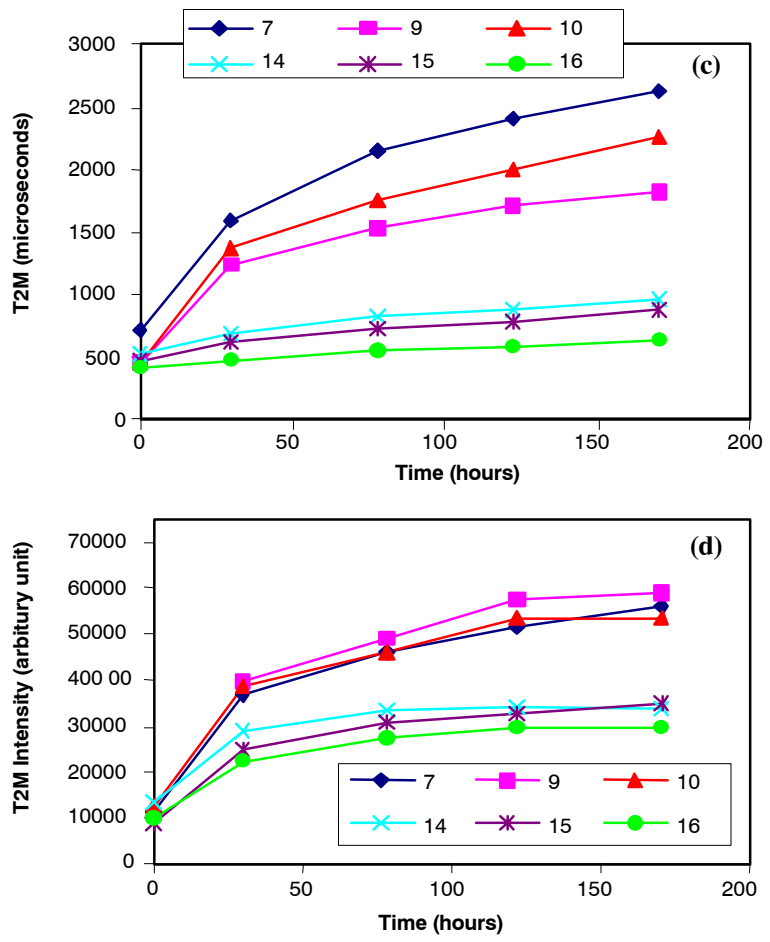

Figure 6. Change of $T 2$ values and the corresponding intensities of the two states of water mobility: (a) short T2 (T2S) change with time, (b) intensity of T2S (I2S) change with time, (c) medium T2 (T2M) change with time, and (d) intensity of T2M (I2M) change with time. 
Table 2. Chemical composition of southern pine and aspen wood (Kultikova, 1999).

\begin{tabular}{|c|c|c|c|c|c|c|c|c|c|c|}
\hline \multirow[b]{3}{*}{ Wood Species } & \multicolumn{6}{|c|}{ Carbohydrate Composition (\%) } & \multicolumn{3}{|c|}{ Lignin $(\%)$} & \multirow{3}{*}{$\begin{array}{c}\text { Ash } \\
\text { Content } \\
(\%)\end{array}$} \\
\hline & \multirow{2}{*}{$\begin{array}{c}\text { Cellulose } \\
\text { Glucan }\end{array}$} & \multicolumn{4}{|c|}{ Hemi-cellulose } & \multirow{2}{*}{$\begin{array}{c}\text { Total } \\
\text { Carbohydrate }\end{array}$} & \multirow{2}{*}{$\begin{array}{c}\text { Acid } \\
\text { Insoluble }\end{array}$} & \multirow{2}{*}{$\begin{array}{c}\text { Acid } \\
\text { Soluble }\end{array}$} & \multirow{2}{*}{$\begin{array}{c}\text { Total } \\
\text { Lignin }\end{array}$} & \\
\hline & & Xylan & Galactan & Arabinan & Mannan & & & & & \\
\hline Southern pine & 43.94 & 6.97 & 2.22 & 0.00 & 15.17 & 68.29 & 25.55 & 0.29 & 25.84 & 0.03 \\
\hline Aspen & 42.95 & 17.04 & 0.00 & 0.00 & 1.85 & 61.85 & 19.24 & 3.07 & 22.31 & 0.43 \\
\hline
\end{tabular}

similar to the "bulk" T2 plot (fig. 3), OSB made from pine or aspen can be differentiated in the T2M/I2M plots. However, the short T2 component and intensity appeared less affected, and the trend of change was inconclusive. The T2S component may correspond to the water tightly bonded with the wood cell walls.

The isotherm sorption characteristics revealed by NMR could be explained by the cluster theory (Goring, 1978; Hartley et al., 1992), considering that water sorption occurs at surface sites, since mold growth is a surface phenomenon on wood-based products. As water first adsorbs to the wood, hydration sites are occupied by single water molecules. With more water added to the wood, the unimolecular hydration continues, but some of the water molecules are attracted to sites already occupied, forming water dimers and perhaps trimers. Upon such cluster formation, the bond to the lignocellulosic substrate is generally expected to be weakened, with the clusters experiencing increased mobility. As the clusters grow in size, the water molecules experience an environment that more and more resembles that of free water. As a consequence, the mobility of the water molecules increases, with the result that the water proton $\mathrm{T} 2$ becomes longer. The biological structure of the OSB substrate determines how tightly the water molecules are bonded and how the T2 values are distributed. Wood species and their chemical compositions, adhesives used, and product processing conditions all affect the structural and hygroscopic properties of the end product. An examination of the chemical composition of the two wood species revealed interesting information (table 2).

The most significant difference in chemical composition between the two wood species is in their mannan contents. Southern pine contains much more mannan. Under a hot-press process for OSB production that involves high pressure, heat, and steam formation, partial hydrolysis of hemicellulose occurs, resulting in the breakdown of mannan to mannose (Hsu et al., 1988). Mannose has antibacterial, antiviral, antiparasitic, and antifungal properties (Elkins, 2003; Mondoa and Kitei, 2002). Nonetheless, the higher mannan content did not render a higher mold resistance in OSB made from southern pine. The level of hydrolysis, mannan content change, and how those chemical changes are related to mold susceptibility will be left for future research. Water mobility as a result of the interaction between moisture and wood substrate plays a more prominent role in determining the mold susceptibility of OSB.

It is important to point out that moisture content and water activity do not truly reflect the water mobility, as measured by the NMR relaxometry and chemometrics analysis. It appeared in this study that water mobility as determined by NMR is a better indicator of water "availability" to mold growth, although more detailed study should be conducted to determine the threshold point of $\mathrm{T} 2$ above which water is available to mold growth. NMR relaxometry is non-invasive and faster than either MC determination or $a_{w}$ measurement, and inexpensive relaxometers are available on the market.

\section{CONCLUSIONS AND RECOMMENDATIONS}

Moisture content determination, water activity measurement, and NMR relaxometry were conducted to evaluate water characteristics in commercial OSB specimens and their relationship to mold susceptibility. Two resin types and two wood species were chosen to represent the most common products available in North America. The following conclusions can be drawn from this study:

- Neither MC nor $a_{w}$ is a reliable indicator of the mold susceptibility of OSB.

- Although the MDI resin reduces moisture intake by OSB, it does not necessarily reduce mold susceptibility.

- The "bulk" T1/T2 measurements can be used to differentiate OSB specimens with different bulk water mobility, but failed as indicators of mold susceptibility.

- NMR relaxometry, together with the distributed exponential analysis, detected that the state of water with the longest $\mathrm{T} 2$ is responsible for the mold susceptibility of OSB.

- Compared with OSB made from aspen, which has only two states of water at up to $170 \mathrm{~h}$ into the isotherm sorption, OSB made from pine has a third state of water that possesses a much longer T2. This third state of water explains why the OSB made from pine has higher mold susceptibility than that made from aspen.

The results of this study suggest that a new protocol for quality control based on NMR relaxometry could be put in place in OSB production. Further study is needed to investigate the relationship between water mobility and FSP. Specifically, since both moisture adsorption and mold growth are localized surface phenomena, mapping the T2 distribution of surface cross-sections using magnetic resonance imaging (MRI) might provide higher resolution and more detailed information related to mold growth. A microbiological technique that can precisely detect the initiation of mold growth is needed so that the threshold point of T2 above which water is available to mold growth can be determined.

\section{ACKNOWLEDGEMENTS}

The authors would like to acknowledge support from Tennessee Agricultural Experiment Station. Thanks go to Trairat Neimsuwan for specimen preparation and some data collection, and to Dr. Svetlana Zivanovic for the determination of water activity.

\section{REFERENCES}

Ablett, S. 1992. Overview of NMR applications in food science. Trends Food Sci. Tech. 3(8/9): 246-250.

Alexander, J., S. Shaler, and W. Wright. 2000. Effect of resin type on OSB durability. In Proc. 4th European Panel Products Symposium, 34-44. Bangor, Wales: University of Wales, The BioComposites Centre. 
Babiak, M., and J. Kudela. 1995. A contribution to the definition of the fiber saturation point. Wood Sci. Tech. 29(3): 217-226.

Beuchat, L. R. 1981. Microbial stability as affected by water activity. Cereal Foods World 26(7): 345-349.

Butler, J. P., S. V. Dawson, and J. A. Reeds. 1981. Estimating solutions of first kind integral equations with nonnegative constraints and optimal smoothing, SIAM J. Numerical Analysis 18(3): 381-397.

Chinachoti, P., and S. J. Schmidt. 1991. Solute-polymer-water interactions and their manifestations. Adv. Exp. Med. Biol. 302: 561-583.

Duckworth, R. B. 1981. Solute mobility in relation to water content and water activity. In Water Activity Influences on Food Quality, 295-317 L. B. Rockland and G. F. Stewart, eds. London, U.K.: Academic Press.

Elkins, R. M. H. 2003. Miracle Sugars. Orem, Utah: Woodland Publishing.

Forest Products Laboratory. 1989. The Encyclopedia of Wood. Revised ed. New York, N.Y.: Sterling Publishing.

Gervais, P., J. P. Fasquel, and P. Molin. 1988. Water relation of fungal spore germination. Applied Microbiology and Biotech. 29(6): 586-592.

Goring, D. A. I. 1978. The effect of cellulose on the structure of water: View 1. In Fibre Water Interactions in Paper-Making, 2: 287-291. London, U.K.: British Paper and Board Industry Federation.

Gu, H., S. Wang, T. Neimsuwan, and S. G. Wang. 2005. Comparison study of commercial OSB flooring products in thickness swell and mechanical performance. Forest Products $J$. 55(12): 239-245.

Halligan, A. F., and A. P. Schniewind. 1972. Effect of moisture on physical and creep properties of particleboard. Forest Products J. 22(4): 41-48.

Hartley, I. D., and M. H. Schneider. 1993. Water vapour diffusion and adsorption characteristics of sugar maple (Acer saccharum, Marsh.) wood polymer composites. Wood Sci. Tech. 27(6): 421-427.

Hartley, I. D., F. A. Kamke, and H. Peemoeller. 1992. Cluster theory for water sorption in wood. Wood Sci. Tech. 26(2): 83-99.

Hills, B. P., K. M. Wright, and P. S. Belton. 1989. NMR studies of water proton relaxation in Sephadex bead suspensions. Molecular Physics 67: 193-208.

Hills, B. P., S. F. Takacs, and P. S. Belton. 1990. A new interpretation of proton NMR relaxation time measurements of water in food. Food Chem. 37(2): 95-111.

Hsu, W. E., W. Schwald, J. Schwald, and J. A. Shields. 1988. Chemical and physical changes required for producing dimensionally stable wood-based composites: Part 1 . Steam pretreatment. Wood Sci. Tech. 22(3): 281-289.

Kakalis, L. T., L. C. Baianu, and T. F. Kumosinski. 1990. Oxygen-17 and proton nuclear magnetic relaxation measurements of soybean hydration and protein-protein interactions in solution. J Agric Food Chem. 38(3): 639-647.

Kalichevsky, M. T., E. M. Jaroszkiewicz, S. Ablett, J. M. V. Blanshard, and P. J. Lillford. 1994. The glass transition of amylopectin measured by DSC, DMTA, and NMR. Carbohydrate Polymer 18(2): 77-88.

Kultikova, E. V. 1999. Structure and properties relationships of densified wood. MS thesis. Blacksburg, Va.: Virginia Tech, Department of Wood Science and Forest Products.

Labuza, T. P., S. Cassil, and A. J. Sinskey. 1972. Stability of intermediate moisture foods: 2. Microbiology. J Food Sci. 37(1): 160-162.

Labuza, T. P., and R. Contreras-Medellin. 1981. Prediction of Moisture Protection Requirements for Foods. Cereal Foods World 26(7): 335-343.

Lai, H. M., and S. J. Schmidt. 1991. Proton, deuterium, and oxygen-17 nuclear magnetic resonance relaxation studies of lactose- and sucrose-water systems. J Agric Food Chem. 39(11): 1921-1926.

Lai, H. M., and S. J. Schmidt. 1993. Mobility of water in various sugar-water systems as studied by oxygen-17 NMR. Food Chem. 46(1): 55-60.

Laks, P. E., D. L. Richter, and G. M. Larkin. 2002. Fungal susceptibility of interior commercial building panels. Forest Prod. J. 52(5): 41-44.

Lang, K. W., and M. P. Steinberg. 1981. Linearization of the water sorption isotherm for homogeneous ingredients over $a_{w}$ 0.30-0.95: Properties of food systems. J Food Sci. 46(5): 1450-1452.

Leistner, L., and W. Rodel. 1976. The stability of intermediate moisture foods with respect to microorganisms. In Intermediate Moisture Foods, 120-137. R. Davies, G. G. Birch, and K. J. Parker, eds. London, U.K.: Applied Science Publishers.

Mondoa, E. I., and M. Kitei. 2002. Sugars That Heal: The New Healing Science of Glyconutrients. New York, N.Y.: Ballantine Publishing Group.

Morris, P., A. Uzunovic, T. Byrne, and D. Yang. 2003. Current research on mold at Forintek. Wood Design Focus 13(2): 15-17.

Niemz, P., and H. Poblete. 1995. Untersuchungen zur gleichgewichtsfeuchte von MDF und Spanplatten. Holz als Rohund Werkstoff 53(6): 368.

Remin, M., R. L. Somorjai, R. Deslauriers, E. J. Princz, and I. C. Smith. 1989. 1H magnetic resonance of human tumors: Analysis of the transverse relaxation of the methylene protons using continuous distributions of relaxation times. NMR Biomed. 2(4): 142-50.

Ross, A. S. 2004. The war on mold: New treatments aiding in fight against ancient fungus. The Engineered Wood J. (Fall). Available at: www.apawood.org/level_b.cfm?content=pub_ewj_arch_f04_ mold.

Ruan, R. R., and P. L. Chen. 1998. Water in Foods and Biological Materials: A Nuclear Magnetic Resonance Approach. Lancaster, Pa.: Technomic Publishing.

Schmidt, S. J. 2004. Water and solids mobility in foods. Advances in Food and Nutrition Research 48: 1-101. London, U.K.: Elsevier Academic Press.

Schmidt, S. J., and H. M. Lai. 1991. Use of NMR and MRI to study water relations in foods. Adv. Exp. Med. Biol. 302: 405-452.

Scott, W. J. 1957. Water relation of food spoilage microorganisms. Adv. Food Res. 7: 83-127.

Sekino, N., A. Suematsu, K. Hideaki, and E. Yasui. 1999. Measurements of sorption isotherms of selected commercial wood-based panels and predictions of moisture content changes in service. Mokuzai Gakkaishi 45(3): 237-243.

Siau, J. E. 1995. Wood: Influence of Moisture on Physical Properties. Blacksburg, Va.: Virginia Tech, Department of Wood Science and Forest Products.

Simpson, W. T. 1973. Predicting equilibrium moisture content of wood by mathematical models. Wood and Fiber Science 5(1): 41-49.

Slade, L., and H. Levine. 1991. Beyond water activity: recent advances based on an alternative approach to the assessment of food quality and safety. Crit. Rev. Food Sci. Nutr. 30(2/3): 115-360.

USDA Forest Products Lab Advanced Housing Research Center. 2003. Common questions and answers about mold. Wood Design Focus 13(2): 17-22.

Wang, S., H. Gu, T. Neimsuwan, and S. G. Wang. 2003. Layer thickness swell and related properties of commercial OSB products: A comparative study. In Proc. 37th International Particleboard and Composite Materials Symposium, 65-76. Pullman, Wash.: Washington State University.

Webb, G. A., P. S. Belton, A. M. Gil, and I. Delgadillo. 2001. Magnetic Resonance in Food Science: A View to the Future. London, U.K.: The Royal Society of Chemistry. 
